\title{
Article
}

\section{Prevalence and factors associated with non-utilization of healthcare facility for childbirth in rural and urban Nigeria: Analysis of a national population-based survey}

Adewuyi, Emmanuel O, Zhao, Yun, Auta, Asa and Lamichhane, Reeta

Available at http://clok.uclan.ac.uk/18603/

Adewuyi, Emmanuel O, Zhao, Yun, Auta, Asa ORCID: 0000-0001-6515-5802 and Lamichhane, Reeta (2017) Prevalence and factors associated with nonutilization of healthcare facility for childbirth in rural and urban Nigeria: Analysis of a national population-based survey. Scandinavian Journal of Public Health, 45 (6). pp. 675-682. ISSN 1403-4948

It is advisable to refer to the publisher's version if you intend to cite from the work. http://dx.doi.org/10.1177/1403494817705562

For more information about UCLan's research in this area go to http://www.uclan.ac.uk/researchgroups/ and search for <name of research Group>.

For information about Research generally at UCLan please go to http://www.uclan.ac.uk/research/

All outputs in CLoK are protected by Intellectual Property Rights law, including Copyright law. Copyright, IPR and Moral Rights for the works on this site are retained by the individual authors and/or other copyright owners. Terms and conditions for use of this material are defined in the policies page. 


\title{
Prevalence and factors associated with non-utilization of healthcare facility for childbirth in rural and urban Nigeria: analysis of a national population-based survey
}

\author{
Authors: \\ Emmanuel O Adewuyi ${ }^{1,2 *}$ (BPharm, MPH), adewuyiemma@gmail.com \\ Yun Zhao² (BSc, MSc, PhD), Y.Zhao@exchange.curtin.edu.au \\ Asa $\operatorname{Auta}^{3}$ (BPharm, MPH, PhD), aauta@uclan.ac.uk \\ Reeta Lamichhane $^{2}$ (Bachelor in Nursing (BN), MPH), rcsindhu@ gmail.com \\ ${ }^{1}$ Federal Ministry of Defense, 2 Division Hospital, Adekunle Fajuyi Cantonment, Odogbo, \\ Ibadan, Oyo State, Nigeria. \\ ${ }^{2}$ Department of Epidemiology and Biostatistics, School of Public Health, Curtin University, \\ Bentley Campus, Perth, Australia. \\ ${ }^{3}$ School of Pharmacy and Biomedical Sciences, University of Central Lancashire, Preston, \\ United Kingdom. \\ * Corresponding author: Emmanuel O Adewuyi \\ Federal Ministry of Defense, 2 Division Hospital, Adekunle Fajuyi Cantonment, Odogbo, \\ Ibadan, Oyo State, Nigeria. \\ Email: adewuyiemma@gmail.com,
}

Word count: 3810 (excluding abstract, reference list and Tables). 


\section{Abstract}

Aims: To assess the rural-urban differences in the prevalence and factors associated with nonutilization of healthcare facility for childbirth (home delivery) in Nigeria.

Methods: Dataset from the Nigeria demographic and health survey, 2013, disaggregated by rural-urban residence was analyzed with appropriate adjustment for the cluster sampling design of the survey. Factors associated with home delivery were identified using multivariable logistic regression analysis.

Results: In rural and urban residence, the prevalence of home delivery were $78.3 \%$ and $38.1 \%$, respectively $(\mathrm{P}<0.001)$. The lowest prevalence of home delivery occurred in the SouthEast region for rural residence (18.6\%) and the South-West region for urban residence (17.9\%). The North-West region had the highest prevalence of home delivery $-93.6 \%$ and $70.5 \%$ in rural and urban residence, respectively. Low maternal as well as paternal education, low antenatal attendance, being less wealthy, the practice of Islam, and living in the North-East, North-West and the South-South regions increased the likelihood of home delivery in both rural and urban residences. Whether in rural or urban residence, birth order of one decreased the likelihood of home delivery. In rural residence only, living in the North-Central region increased the chances of home delivery. In urban residence only, maternal age $\geq 36$ years decreased the likelihood of home delivery, while 'Traditionalist/other' religion and maternal age $<20$ years increased it.

Conclusion: The prevalence of home delivery was much higher in rural than urban Nigeria and the associated factors differ to varying degrees in the two residences.

Keywords: Facility delivery; home delivery; maternal health services; Nigeria; rural-urban differences. 


\section{Introduction}

From the inception of the 'safe motherhood' in the 1980s to the launch of the 'global strategy for women's and children's health' in 2010, the commitment to improved maternal health continues to be a subject of increasing significance, worldwide $[1,2]$. To demonstrate the importance of such a global commitment, maternal health was accorded a high priority in the Millennium Development Goals (MDG 5), with a target of $75 \%$ reduction in Maternal Mortality Ratio (MMR: maternal deaths per 100000 live births) by the year 2015 [3]. It is imperative to appreciate the measurable progress made so far, with a decline of $43.9 \%$ in the global MMR between 1990 and 2015 [1]. However, a convincing body of evidence suggests that maternal mortality (the death of women during pregnancy, childbirth, or in 42 days after delivery) remains a theme of considerable public health concern, especially, in the developing world [3, 4].

In the year 2015, an estimated 303000 maternal mortality was recorded, globally, 99\% of which occurred in the developing regions of the world, with Nigeria alone accounting for approximately $19 \%$ of the mortalities [4]. Based on current evidence, Nigeria, followed by India, had the highest number of maternal deaths in 2015 - approximately 58000 and 45000 deaths, respectively [4]. Sadly, the majority of these mortalities were uncalled for as they are generally preventable by utilizing healthcare facilities for childbirth (institutional or facility-based delivery) [5]. The rationale for this premise is well-established. Obstetric complications of pregnancy (hemorrhage, infections, obstructed labor, unsafe abortion, and eclampsia) are known leading causes of maternal mortality $[6,7]$. Also, over $60 \%$ of maternal deaths occur in the period around childbirth and few hours/days thereafter [6, 7]. Thus, by simply accessing 
essential/emergency obstetric care services through institutional delivery, several needless maternal and newborn mortalities could be averted [6].

Granted that a growing body of evidence now supports the provision of obstetric care services at the home level in some developed countries [8,9], the enabling environments for such services are rarely available in many countries, particularly, in a developing country like Nigeria [8]. Thus, utilizing healthcare facility remains the best means of accessing obstetric care services in the majority of settings [8]. This fact notwithstanding, health facility delivery is poorly utilized in many developing countries, and several factors ranging from personal- to households - and community-level have been implicated $[5,10,11]$.

As indicated in the report of the demographic and health survey, home delivery is considerably high in Nigeria (63\%), and there has been only a marginal decrease in its rate over the years in the country - from $66 \%$ in 2003 to $63 \%$ in 2013 [12]. This rate of reduction is low compared to the case in similar developing countries like Ghana where home delivery has decreased from 54\% in 2003 to 27\% in 2014 [13]; and Nepal which has recorded an impressive reduction in the rate of home delivery within a short time - from $79.2 \%$ in 2006 to $46.5 \%$ in 2014 [14].

So far, a few studies have assessed factors associated with utilization of maternal care services including the place of childbirth in Nigeria [15, 16]. For instance, Dahiru and Oche [15] reported parity, residence, maternal and paternal education as predictors of institutional delivery in the country. Another study found region of residence, maternal education and ethnicity to be significantly associated with the place of childbirth in Nigeria [16]. However, all the studies to date were based only on national average of estimates (using pooled datasets) and so limited as they did not investigate the within population variations such as the rural-urban differences. The use of pooled dataset is known to mask the within population variations, thus, there is an existing 
knowledge gap with respect to the rural-urban differences in the utilization of healthcare facilities for childbirth in Nigeria. The present study aims to bridge the gap by examining the rural-urban differentials in the prevalence and factors associated with home delivery in Nigeria.

The rural-urban dichotomy approach adopted in this study agrees with international consensus and the WHO's framework for measuring universal health coverage which demands that studies be disaggregated along socioeconomic and/or geographic divides [7, 17, 18]. Such data disaggregation approach may help capture context-specific factors which could be lost to the use of 'one-size-fits-all' method of pooled datasets [7, 19].

In light of the ambitious targets for universal health coverage [17], and the critical need for a speedy reduction of maternal and neonatal mortalities in Nigeria [2, 4], this study provides evidence-informed knowledge for addressing the challenge of home delivery in the country.

\section{Methods}

\section{Sample and study variables}

Dataset from the 2013 Nigeria demographic and health survey (NDHS), a nationally representative population-based survey, was analyzed [12]. A stratified three-stage cluster sampling design was used for sample selection in the 2013 NDHS. The design consisted of 904 clusters, 372 of which were in urban areas and 532 in rural areas. Interviewer-administered questionnaires were used for data collection and out of 40320 representative households selected for the survey, 38522 were interviewed successfully. A total of 38948 eligible women aged 15 - 49 years were interviewed (15 545 in urban residence and 23403 in rural residence). However, the sample included in this study was limited to a total of 30043 mothers (20 193 in rural and 
9850 in urban residence) who gave information on the place of their last live childbirth in the five years preceding the survey. Women who had multiple births were not included in analyses. A comprehensive report on the setting, the questionnaires used and the sampling procedures for the 2013 NDHS has been published [12].

The main outcome variable for this study was 'non-utilization of health facility for childbirth'(home delivery), consisting of deliveries at 'respondent's home' and 'other home' [12]. Responses to the question on place of delivery collected in the 2013 NDHS was re-coded as ' 0 ' for home delivery and ' 1 ' for health facility (institutional) delivery. Health facility delivery comprised of both public (government hospital, government health centre, government health post and other public sector facilities) and private (private hospital, private clinic, and other private medical sector) health facilities [12].

Independent variables were selected based on the objective of this study and the review of previous studies $[5,10,11]$. The variables were broadly categorized into three - individual-, household - and community-level variables [5]. The individual-level variables were: maternal and paternal (husband/partner) education level (none, primary and secondary/higher), maternal and paternal (husband/partner) occupation (working and not working), maternal age $(<20,20-$ 35 , and $\geq 36$ years) and maternal age at first childbirth ( $<20$ and $\geq 20$ years).

Other individual-level variables included antenatal attendance (none, $1-3$, and $\geq 4$ ), birth order (1, 2-3 and $\geq 4)$, maternal marital status (married/cohabiting and unmarried [never married, widowed, divorced, separated]). Households variables assessed were religion (Traditionalist/others, Islam and Christianity), and wealth index (poor [poorest and poorer'], middle and rich [richer and richest]). Community level variables included region of residence 
(the six geo-political zones in Nigeria: North-Central, North-East, North-West, South-East, South-South and South-West). Residence was categorized as rural and urban.

\section{Statistical analysis}

Frequency tabulation and Chi square test were carried out to compute the prevalence of home and facility delivery as well as assess the statistical significance of the unadjusted relationship between the outcome variable (home delivery) and the independent variables. Multivariable logistic regression analyses were conducted to examine the adjusted association between the outcome variable and the independent variables using the hierarchical modelling method [5, 19]. Three parsimonious regression models were built by using a backward elimination method in the multiple regression analysis procedures. Specifically, in Model I, all the individual-level variables were entered initially and only the significant variables at the $10 \%$ level $(\mathrm{P}<0.1)$ were retained. Then all household-level variables joined in with those variables retained in Model I to establish Model II. Again only those found to be significant at the $10 \%$ level (with a p <0.1) were retained in Model II. In the final model (Model III), the impact of all community-level variables was assessed with the adjustment of those retained in Model II. Variables significant at the 5\% significance level $(\mathrm{P}<0.05)$ in the final model were retained and reported along with their adjusted odds ratio (AOR), corresponding 95\% confidence interval (CI) and P-value. AOR represents the measure of association obtained following adjustment for other factors/confounders.

The analysis procedure above was carried out separately for data disaggregated by rural and urban residence. In all analyses, adjustment was made for the multistage cluster sampling method of the 2013 NDHS to eliminate sampling bias and, ensure precise estimations. Variables 
of sampling strata, sampling cluster and sampling weight provided in the 2013 NDHS were used to declare the survey design in the Complex Samples analysis procedure. Missing values were not included in analyses. All analyses were conducted using the SPSS, version 21.0, released 2012 (IBM, Armonk, NY, USA).

\section{Results}

\section{Prevalence of home delivery by rural and urban residence}

Table 1 presents the results of the prevalence of the place of childbirth in Nigeria by rural and urban residence. Within five years preceding the 2013 NDHS, a total of 30043 mothers gave information on their place of last childbirth (overall residence) - 20193 in rural and 9850 in urban residence - and those were included in this study. The prevalence of home delivery obtained by a separate Chi-square test was $78.3 \%$ and $38.1 \%$ in rural and urban residence, respectively $(\mathrm{P}<0.001)$.

The North-West region had the highest prevalence of home delivery $-93.6 \%$ and $70.5 \%$ in rural and urban residence, respectively. The lowest prevalence of home delivery occurred in the South-East region for rural residence $(18.6 \%)$ and in the South-West region for urban residence $(17.9 \%)$. Irrespective of residence type, mothers who had no education, or who had attended no antenatal care, or whose age was below 20 years (teen), or who were classed in the poor wealth index category had a higher prevalence of home delivery. Also, the prevalence of home delivery was highest in households that practiced Islamic religion in the rural residence $(89.1 \%)$ and in households that profess 'Traditional/other' religion in urban residence $(62.6 \%)$. 


\section{Factors associated with home delivery in rural and urban Nigeria}

Table 2 presents the results of factors associated with home delivery in both rural and urban Nigeria. In rural residence, mothers who were not educated and those with only primary education had $80 \%$ and $29 \%$ increased likelihood of home delivery, respectively. Similarly, greater chances of home delivery were associated with lack of paternal education (48\%) and paternal primary education (29\%). The likelihood of home delivery was 9-fold higher among rural mothers who did not attend antenatal care and 1.8-fold higher in those with less than four times antenatal care attendance. Mothers who belonged to the poor and middle wealth index categories had two-fold and 1.4-fold increased chances of home delivery, respectively.

Also, compared to their counterparts in the South-East region, the likelihood of home delivery was higher in rural mothers who resided in the North-Central (2.3-fold greater), North-East (4.6fold greater), North-West (6.5-fold greater) and the South-South (4.5-fold greater) regions. Birth order of one decreased the likelihood of home delivery by $42 \%$ in rural residence while the practice of Islamic religion increased it by $60 \%$.

In urban residence, the likelihood of home delivery was greater among mothers who lacked education (2.1-fold higher), had only primary education (1.7-fold higher), had attended no antenatal care (10-fold higher), as well as those whose antenatal attendance was less than four times (2.2-fold higher). Also, lack of paternal education and paternal primary education increased the risk of home delivery by $52 \%$ and $34 \%$, respectively. Increased likelihood of home delivery was equally found among urban mothers categorized in the poor wealth index (3-fold greater), and the middle wealth index (nearly two-fold greater). Similarly, compared to their counterparts in the South - East region, chances of home delivery was greater among urban 
mothers residing in the North-East (2.5-fold higher), North-West (4.2-fold higher) and the SouthSouth (2.8-fold higher).

The likelihood of home delivery was equally greater among urban mothers who practiced 'Traditionalist/other' religion (3-fold greater), whose age was < 20 years (1.7-fold greater), and those whose age at first childbirth was less than 20 years (1.2-fold greater); these were strikingly different from the findings in rural residence. Conversely, maternal age $\geq 36$ years decreased the likelihood of home delivery by $23 \%$, the finding was equally different from the results in rural residence. Also, unlike in rural residence, living in the North-Central region was not predictive of home delivery in urban residence. On the other hand and as the case in rural residence, birth order of one decreased the likelihood of home delivery by $42 \%$ while the practice Islamic religion increased it by $80 \%$ in urban residence.

\section{Discussion}

This study investigated the rural-urban differences in the prevalence and factors associated with home delivery in Nigeria. The prevalence of home delivery was $78.3 \%$ and $38.1 \%$ in rural and urban residences, respectively $(\mathrm{P}<0.001)$. Based on the multivariable analysis, maternal and paternal education level, birth order, antenatal attendance, and wealth index, were consistently associated with home delivery in both rural and urban residences. Other factors differ to varying degrees in the residences including maternal age, region of residence, religion, and maternal age at first childbirth. These results reveal variations in the prevalence and varying degrees of differences in factors associated with home delivery in rural and urban Nigeria.

The prevalence of home delivery was over two-fold higher in rural compared to urban residence. This finding may be blamed on several factors including low presence of healthcare facilities, 
barrier of physical access, effects of socio-cultural practices/beliefs and poverty in rural Nigeria [20]. There is evidence that healthcare facilities are more concentrated in urban than rural Nigeria, yet, over $60 \%$ of Nigerian population resides in the rural areas $[12,20]$. In a state in South-East Nigeria, approximately $85 \%$ of privately owned and $56 \%$ of government health facilities, capable of offering basic emergency obstetric care services were located in urban areas [21]. Also, where facilities exist in rural residence, they may be sparsely distributed thus limiting physical access to some sections of rural communities $[12,20]$.

Further, compared to urban areas, health facilities may be understaffed, ill-equipped or both in rural Nigeria $[12,20]$. For instance, evidence suggests that residents in urban Nigeria have three times more access to doctors and two times more to nurses/midwives compared to their counterparts in rural areas [22]. These and other factors such as a poor system of road network, may contribute to low/non-utilization of health facilities for childbirth in rural residence [23]. Low antenatal attendance was overwhelmingly associated with home delivery in both rural and urban residences. The higher the antenatal attendance the less likely was home delivery. This finding agrees with previous evidence showing that mothers who attend antenatal services would more likely patronize facility-based delivery [5, 24]. Similarly, low educational attainment (both maternal and paternal) and poor wealth index were associated with higher chances of home delivery in all residences but the strength of associations was stronger in urban residence These two factors (lack of education and poor wealth index) are perhaps the most frequently cited for increased probability of home delivery in the literature [5, 24].Even where access to institutional delivery was freely available in rural Tanzania, home delivery was substantially more likely among the poor and uneducated mothers [24]. The poor and the uneducated often lack economic empowerment, necessary health awareness, confidence and cognitive skills for informed 
decision-making, thus, they are less likely to patronize institutional delivery [5, 25]. Irrespective of rural-urban residence, birth order of one was associated with a decreased likelihood of home delivery. This result is consistent with findings in studies [5, 24]. A likely explanation would be the impact of unpleasant delivery experiences in women with higher parity and/or the belief that childbirth is a natural process following past deliveries that were complication-free $[5,16]$. Hence, addressing misconceptions on pregnancy and childbirth using evidence-based behavior change communication method [26] may contribute to a better utilization of institutional delivery in Nigeria.

Both maternal age and maternal age at first childbirth were not associated with home delivery in rural residence, however, in urban residence, maternal age $\geq 36$ years reduced the chances of home delivery while maternal age $<20$ years increased it. The result for maternal age $<20$ years does not agree with a Tanzanian study [27], however, it does agree with findings in previous analyses of NDHS $[12,15,16]$. A probable explanation would be that teenage mothers face greater challenges accessing healthcare services in Nigeria. This category of mothers would more likely be uneducated, unemployed, initiated early into sex/family life, vulnerable to the challenge of unwanted pregnancies/abortions and poverty [12]. These factors coupled with religious and cultural biases may deny such women access to reproductive health services contributing in some ways to increased chances of home delivery [12].

'Furthermore, women in the northern regions (except the North-Central in urban residence), and those in the South-South were more likely to deliver their babies at home in both rural and urban residences. Although the impact of religion and traditional practices may be implicated [28], these findings are more likely to be a reflection of educational and socioeconomic differences between the regions in Nigeria [16]. Compared to the South-West and the South-East which have 
a better profile for institutional delivery, the northern regions are known to be educationally and socioeconomically disadvantaged [12,29]. Also, the South-South region is reported to have suffered low socioeconomic development blamable on infrastructure deficits, high unemployment rates and environmental degradation [29]. Conversely, given their capacity to cause a breakdown of health facilities, the security challenges in parts of North-East, North-West (insurgency) and South-South (militancy), may have contributed in some ways to the low/nonutilization of institutional delivery in the named regions [12, 29].

Compared to their counterparts who practiced Christianity, home delivery was more likely in women professing Islamic religion both in rural and urban residence. Similarly, women who belonged to the 'Traditionalist/other' religion in urban residence had over three-fold increased chances of home delivery than those who professed Christianity. The finding for traditional or other religions may be an extension of the impacts of traditional beliefs and practices in Nigeria, although the result was probably expected in the rural residence where traditional religion would ordinarily be more prominent. The finding in respect of Islamic religion compares well with studies reporting low utilization of maternal services among the Muslims which may be due to religious obligations such as require Muslim women to avoid undue exposure of their body [28, 30]. The use of a nationally representative dataset disaggregated by rural-urban residence is a remarkable strength of this study, and in view of the large sample size of the dataset, disaggregation does not undermine generalizability. Nevertheless, this study is limited in that data were collected retrospectively and recall bias was likely. Also, it is not possible to estimate causal relationship owing to the cross-sectional design of the survey. 


\section{Conclusion and recommendations}

Rural-urban differences exist in the prevalence and factors associated with home delivery in Nigeria with rural residence having higher prevalence. Some factors were associated with home delivery in the two residences including maternal and paternal education level, birth order, antenatal attendance, and wealth index. Other factors differ to varying degrees in the residences and included maternal age, region of residence, religion, and maternal age at first childbirth. The critical need to bridge the rural-urban differences in access to health facility delivery in Nigeria was unveiled in this study. Rural women, generally, and women in the rural and urban northern regions (except urban North-Central) as well as in the South-South region should be given priority attention in program design.

Also, future interventions would need to focus on improving antenatal attendance, maternal and paternal education attainments as well as bridging the gap between the rich and the poor both in rural and urban residences. Target-specific programs are needed for teenage mothers in urban residence just as it is imperative to put religion in perspective, especially, for women professing Traditional/other religion in urban residence, and Islamic religion both in rural and urban residence. A multidimensional approach that addresses misconceptions about pregnancy and childbirth, including evidence-based behavior change communication method may contribute to a better utilization of institutional delivery both in rural and urban Nigeria.

\section{Acknowledgements:}

The authors gratefully appreciate ICF International, USA, for providing the NDHS dataset for this study. 


\section{Funding: None}

\section{Conflict of interest: None}

\section{Ethical Consideration:}

This study was based on a secondary analysis of anonymous public use data, hence, no ethical clearance was required. Permission to use the data was obtained from ICF international.

\section{References}

1. Alkema, L., et al., Global, regional, and national levels and trends in maternal mortality between 1990 and 2015, with scenario-based projections to 2030: a systematic analysis by the UN Maternal Mortality Estimation Inter-Agency Group. The Lancet, 2016. 387(10017): p. 462-474.

2. World Health Organization and UNICEF, Trends in maternal mortality: 1990 to 2013: estimates by WHO, UNICEF, UNFPA, The World Bank and the United Nations Population Division: executive summary. 2014.

3. Kassebaum, N.J., et al., Global, regional, and national levels and causes of maternal mortality during 1990-2013: a systematic analysis for the Global Burden of Disease Study 2013. Lancet, 2014. 384(9947): p. 980-1004.

4. WHO, et al., United Nations Population Division. Trends in maternal mortality, 1990 to 2015. 2015. 32(5): p. 1-55.

5. Khanal, V., et al., Factors associated with non-utilisation of health service for childbirth in TimorLeste: evidence from the 2009-2010 Demographic and Health Survey. BMC international health and human rights, 2014. 14(1): p. 1.

6. Bhandari, T. and G. Dangal, Emergency obstetric care: Strategy for reducing maternal mortality in developing countries. Nepal Journal of Obstetrics and Gynaecology, 2014. 9(1): p. 8-16.

7. UNICEF, Committing to Child Survival: A Promise Renewed, Progress Report 2014. 2014. New York, USA: UNICEF, 2015.

8. Wilbur, M.B., S. Little, and L.M. Szymanski, Is Home Birth Safe? New England Journal of Medicine, 2015. 373(27): p. 2683-2685.

9. Brocklehurst, P., et al., Perinatal and maternal outcomes by planned place of birth for healthy women with low risk pregnancies: the Birthplace in England national prospective cohort study. BMJ, 2011. 343(7840): p. d7400.

10. Karkee, R., C.W. Binns, and A.H. Lee, Determinants of facility delivery after implementation of safer mother programme in Nepal: a prospective cohort study. BMC pregnancy and childbirth, 2013. 13(1): p. 1. 
11. Kitui, J., S. Lewis, and G. Davey, Factors influencing place of delivery for women in Kenya: an analysis of the Kenya demographic and health survey, 2008/2009. BMC Pregnancy and Childbirth, 2013. 13(1): p. 1.

12. National Population Commission (NPC) [Nigeria] and ICF International, Nigeria Demographic and Health Survey 2013. 2014: Abuja, Nigeria and Rockville, Maryland, USA: NPC and ICF International.

13. Ghana Statistical Service (GSS), G.H.S.G., and ICF Macro. 2015. Ghana Demographic and Health Survey 2014. Accra, Ghana: GSS, GHS, and ICF Macro.

14. Målqvist, M., A. Pun, and A. KC, Essential newborn care after home delivery in Nepal. Scandinavian Journal of Public Health, 2016: p. 1403494816683572.

15. Dahiru, T. and O.M. Oche, Determinants of antenatal care, institutional delivery and postnatal care services utilization in Nigeria. Pan African Medical Journal, 2015. 22(1).

16. Ononokpono, D.N. and C.O. Odimegwu, Determinants of maternal health care utilization in Nigeria: a multilevel approach. Pan African Medical Journal, 2014(ARTISSUE).

17. World Health Organisation and World Bank Group, Monitoring progress towards universal health coverage at country and global levels: framework, measures and targets. 2014 Geneva: WHO

18. Hosseinpoor, A.R., et al., Equity-oriented monitoring in the context of universal health coverage. PLoS Med, 2014. 11(9): p. e1001727.

19. Adewuyi, E.O. and Y. Zhao, Determinants of neonatal mortality in rural and urban Nigeria: Evidence from a population-based national survey. Pediatrics International, 2017. 59(2): p. 190200.

20. Federal Ministry of Health, Saving newborn lives in Nigeria: Newborn health in the context of the Integrated Maternal, Newborn and Child Health Strategy. 2nd edition. Abuja: Federal Ministry of Health, Save the Children, Jhpiego. 2011.

21. Okonkwo, J. and C. Ibeh, The contribution of privately owned hospitals in the provision of essential obstetric care in Nigeria. Nigerian journal of clinical practice, 2006. 9(2): p. 159-163.

22. Chankova, S., et al. Catalyzing human resources mobilization: A look at the situation in Nigeria. in Global Health Council Annual Conference, Washington, DC. 2007.

23. Babalola, S. and A. Fatusi, Determinants of use of maternal health services in Nigeria-looking beyond individual and household factors. BMC pregnancy and childbirth, 2009. 9(1): p. 1.

24. Kruk, M.E., et al., Who is left behind on the road to universal facility delivery? A cross-sectional multilevel analysis in rural Tanzania. Tropical Medicine \& International Health, 2015. 20(8): p. 1057-1066. 
25. Diderichsen, F., et al., Health Inequality-determinants and policies. Scandinavian Journal of Public Health, 2012. 40(8_suppl): p. 12-105.

26. Adewuyi, E.O. and K. Adefemi, Behavior Change Communication Using Social Media: A Review. International Journal of communication and health, 2016. 9: p. 109 - 116.

27. Mrisho, M., et al., Factors affecting home delivery in rural Tanzania. Tropical Medicine \& International Health, 2007. 12(7): p. 862-872.

28. Solanke, B.L., et al., Religion as a Social Determinant of Maternal Health Care Service Utilisation in Nigeria. African Population Studies, 2015. 29(2): p. 1868-1881.

29. Smallman, C., et al., Multinational oil companies' CSR initiatives in Nigeria: The scepticism of stakeholders in host communities. Managerial Law, 2007. 49(5/6): p. 218-235.

30. Ganle, J.K., Why Muslim women in Northern Ghana do not use skilled maternal healthcare services at health facilities: a qualitative study. BMC international health and human rights, 2015. 15(1): p. 1 
Table 1: Prevalence of facility and home delivery by rural and urban residence in Nigeria

\begin{tabular}{|c|c|c|c|c|c|c|}
\hline \multirow[t]{2}{*}{ Variables } & \multicolumn{3}{|l|}{ Rural ( $N=20193)$} & \multicolumn{3}{|l|}{ Urban $(\mathrm{N}=9850)$} \\
\hline & $\begin{array}{l}\text { Facility delivery } \\
{[\mathrm{n}=4670]} \\
\%(95 \% \mathrm{CI})\end{array}$ & $\begin{array}{l}\text { Home delivery } \\
{[\mathrm{n}=15523]} \\
\%(95 \% \mathrm{CI})\end{array}$ & $\mathbf{P}$ & $\begin{array}{l}\text { Facility delivery } \\
{[\mathrm{n}=6298]} \\
\%(95 \% \mathrm{CI})\end{array}$ & $\begin{array}{l}\text { Home delivery } \\
{[\mathrm{n}=\mathbf{3 5 5 2}]} \\
\%(95 \% \mathrm{CI})\end{array}$ & $\mathbf{P}$ \\
\hline $\begin{array}{l}\text { Maternal education } \\
\text { level }\end{array}$ & & & $<0.001$ & & & $<0.001$ \\
\hline None & $8.3(7.2-9.6)$ & $91.7(90.4-92.8)$ & & $24.5(20.5-28.9)$ & $75.5(71.1-79.5)$ & \\
\hline Primary & $33.1(29.9-36.5)$ & $66.9(63.5-70.1)$ & & $54.6(49.7-59.4)$ & $45.4(40.6-50.3)$ & \\
\hline Secondary/Higher & $57.0(53.7-60.3)$ & $43.0(39.7-46.3)$ & & $79.4(76.9-81.8)$ & $20.6(18.2-23.1)$ & \\
\hline $\begin{array}{l}\text { Paternal } \\
\text { (husband/partner) } \\
\text { education level }\end{array}$ & & & $<0.001$ & & & $<0.001$ \\
\hline None & $7.3(6.3-8.4)$ & $92.7(91.6-93.7)$ & & $22.7(18.6-27.4)$ & $77.3(72.6-81.4)$ & \\
\hline Primary & $25.7(22.9-28.7)$ & $74.3(71.3-77.1)$ & & $59.5(54.4-64.5)$ & $40.5(35.5-45.6)$ & \\
\hline Secondary/Higher & $44.2(41.0-47.4)$ & $55.8(52.6-59.0)$ & & $72.7(69.5-75.7)$ & $27.3(24.3-30.5)$ & \\
\hline Maternal occupation & & & $<0.001$ & & & $<0.001$ \\
\hline Not working & $15.8(13.4-18.5)$ & $84.2(81.5-86.6)$ & & $53.3(48.1-58.4)$ & $46.7(41.6-51.9)$ & \\
\hline Working & $24.5(22.5-26.7)$ & $75.5(73.3-77.5)$ & & $64.7(61.3-68.0)$ & $35.3(32.0-38.7)$ & \\
\hline $\begin{array}{l}\text { Paternal } \\
\text { (husband/partner) } \\
\text { occupation }\end{array}$ & & & $<0.001$ & & & 0.238 \\
\hline Not working & $43.9(31.3-57.4)$ & $56.1(42.6-68.7)$ & & $69.5(56.0-80.2)$ & $30.5(19.8-44.0)$ & \\
\hline Working & $21.3(19.5-23.2)$ & $78.7(76.8-80.5)$ & & $61.6(58.1-65.0)$ & $38.4(35.0-41.9)$ & \\
\hline Maternal age & & & & & & \\
\hline$<20$ years & $18.6(15.8-21.9)$ & $81.4(78.1-84.2)$ & 0.106 & $48.6(39.4-57.9)$ & $51.4(42.1-60.6)$ & 0.008 \\
\hline $20-35$ years & $21.7(19.7-23.7)$ & $78.3(76.3-80.3)$ & & $62.8(59.3-66.1)$ & $37.2(33.9-40.7)$ & \\
\hline$\geq 36$ years & $22.8(20.3-25.4)$ & $77.2(74.6-79.7)$ & & $59.9(55.1-64.6)$ & $40.1(35.4-44.9)$ & \\
\hline Birth order & & & $<0.001$ & & & $<0.001$ \\
\hline 1 & $31.0(28.3-33.8)$ & $69.0(66.2-71.7)$ & & $73.2(69.5-76.6)$ & $26.8(23.4-30.5)$ & \\
\hline $2-3$ & $23.1(20.7-25.7)$ & $76.9(74.3-79.3)$ & & $66.8(62.8-70.6)$ & $33.2(29.4-37.2)$ & \\
\hline$\geq 4$ & $17.4(15.8-19.1)$ & $82.6(80.9-84.2)$ & & $51.4(47.6-55.3)$ & $48.6(44.7-52.4)$ & \\
\hline $\begin{array}{l}\text { Maternal age at first } \\
\text { child birth }\end{array}$ & & & $<0.001$ & & & $<0.001$ \\
\hline$<20$ years & $16.0(14.5-17.7)$ & $84.0(82.3-85.5)$ & & $46.6(42.7-50.6)$ & $53.4(49.4-57.3)$ & \\
\hline$\geq 20$ years & $34.0(31.2-36.9)$ & $66.0(63.1-68.8)$ & & $73.6(70.5-76.5)$ & $26.4(23.5-29.5)$ & \\
\hline Marital status & & & $<0.001$ & & & \\
\hline Unmarried & $35.9(30.1-42.2)$ & $64.1(57.8-69.9)$ & & $62.7(56.8-68.2)$ & $37.3(31.8-43.2)$ & 0.780 \\
\hline Married/cohabiting & $21.1(19.3-23.0)$ & $78.9(77.0-80.7)$ & & $61.8(58.3-65.2)$ & $38.2(34.8-41.7)$ & \\
\hline Antenatal visit & & & $<0.001$ & & & $<0.001$ \\
\hline None & $3.5(2.9-4.3)$ & $96.5(95.7-97.1)$ & & $9.7(7.0-13.5)$ & $90.3(86.5-93.0)$ & \\
\hline $1-3$ visits & $23.0(20.1-26.2)$ & $77.0(73.8-79.9)$ & & $38.3(33.5-43.4)$ & $61.7(56.6-66.5)$ & \\
\hline$\geq 4$ visits & $45.6(42.7-48.6)$ & $54.4(51.4-57.3)$ & & $73.8(71.2-76.3)$ & $26.2(23.7-28.8)$ & \\
\hline Wealth index & & & $<0.001$ & & & $<0.001$ \\
\hline Poor & $9.6(8.3-10.9)$ & $90.4(89.1-91.7)$ & & $29.8(21.9-39.2)$ & $70.2(60.8-78.1)$ & \\
\hline Middle & $35.9(32.5-39.5)$ & $64.1(60.5-67.5)$ & & $39.6(34.1-45.3)$ & $60.4(54.7-65.9)$ & \\
\hline Rich & $59.3(54.9-63.5)$ & $40.7(36.5-45.1)$ & & $71.5(68.1-74.6)$ & $28.5(25.4-31.9)$ & \\
\hline Religion & & & $<0.001$ & & & $<0.001$ \\
\hline Traditionalist/other & $18.2(9.7-31.5)$ & $81.8(68.5-90.3)$ & & $37.4(20.6-57.9)$ & $62.6(42.1-79.4)$ & \\
\hline Islam & $10.9(9.3-12.6)$ & $89.1(87.4-90.7)$ & & $43.8(39.3-48.4)$ & $56.2(51.6-60.7)$ & \\
\hline Christianity & $47.3(43.7-50.9)$ & $52.7(49.1-56.3)$ & & $80.0(77.5-82.3)$ & $20.0(17.7-22.5)$ & \\
\hline
\end{tabular}




\begin{tabular}{|c|c|c|c|c|c|c|}
\hline \multicolumn{7}{|l|}{ Residence } \\
\hline Rural & $21.7(19.8-23.6)$ & $78.3(76.4-80.2)$ & $<0.001$ & - & - & - \\
\hline Urban & - & - & - & $61.9(58.5-65.1)$ & $38.1(34.9-41.5)$ & $<0.001$ \\
\hline Region of residence & & & $<0.001$ & & & $<0.001$ \\
\hline North-Central & $37.1(32.2-42.3)$ & $62.9(57.7-67.8)$ & & $74.6(64.2-82.8)$ & $25.4(17.2-35.8)$ & \\
\hline North-East & $12.3(9.9-15.2)$ & $87.7(84.8-90.1)$ & & $41.2(31.9-51.3)$ & $58.8(48.7-68.1)$ & \\
\hline North-West & $6.4(4.8-8.4)$ & $93.6(91.6-95.2)$ & & $29.5(23.1-36.8)$ & $70.5(63.2-76.9)$ & \\
\hline South-West & $59.0(46.1-70.8)$ & $41.0(29.2-53.9)$ & & $82.1(78.1-85.5)$ & $17.9(14.5-21.9)$ & \\
\hline South-South & $39.3(33.9-45.1)$ & $60.7(54.9-66.1)$ & & $68.9(61.8-75.3)$ & $31.1(24.7-38.2)$ & \\
\hline South-East & $81.4(74.8-86.5)$ & $18.6(13.5-25.2)$ & & $78.9(73.2-83.6)$ & $21.1(16.4-26.8)$ & \\
\hline
\end{tabular}


Table 2: Factors associated with home delivery in Nigeria by rural-urban residence

\begin{tabular}{|c|c|c|c|c|c|c|}
\hline \multirow[t]{2}{*}{ Variables } & \multicolumn{3}{|l|}{ Rural } & \multicolumn{3}{|l|}{ Urban } \\
\hline & AOR & $95 \% \mathrm{CI}$ & $\mathbf{P}$ & AOR & $95 \% \mathrm{CI}$ & $\mathbf{P}$ \\
\hline Maternal education level & - & - & $<0.001 *$ & - & - & $<0.001 *$ \\
\hline None & 1.888 & $1.533-2.324$ & $<0.001 *$ & 2.142 & $1.652-2.779$ & $<0.001 *$ \\
\hline Primary & 1.286 & $1.096-1.510$ & $0.002 *$ & 1.709 & $1.323-2.209$ & $<0.001 *$ \\
\hline Secondary/Higher & 1.000 & (Reference) & - & 1.000 & (Reference) & - \\
\hline \multicolumn{7}{|l|}{ Paternal (husband/partner) } \\
\hline education level & - & - & $<0.001 *$ & - & - & $0.002 *$ \\
\hline None & 1.476 & $1.197-1.820$ & $<0.001 *$ & 1.517 & $1.188-1.937$ & $0.001 *$ \\
\hline Primary & 1.288 & $1.083-1.531$ & $0.004 *$ & 1.338 & $1.034-1.731$ & $0.027 *$ \\
\hline Secondary/Higher & 1.000 & (Reference) & - & 1.000 & (Reference) & - \\
\hline Maternal age & - & - & - & - & - & $0.007 *$ \\
\hline$<20$ years & - & - & - & 1.673 & $1.059-2.642$ & $0.027 *$ \\
\hline$\geq 36$ years & & & & 0.774 & $0.632-0.948$ & $0.013^{*}$ \\
\hline $20-35$ years & - & - & - & 1.000 & (Reference) & - \\
\hline Birth order & - & - & $<0.001 *$ & - & - & $<0.001 *$ \\
\hline 1 & 0.580 & $0.485-0.693$ & $<0.001 *$ & 0.579 & $0.442-0.759$ & $<0.001 *$ \\
\hline $2-3$ & 0.980 & $0.848-1.133$ & 0.786 & 0.896 & $0.718-1.117$ & 0.328 \\
\hline$\geq 4$ & 1.000 & (Reference) & - & 1.000 & (Reference) & - \\
\hline Maternal age at first child & - & - & - & & & \\
\hline birth & - & - & - & - & - & $0.007 *$ \\
\hline$<20$ years $($ Teen $)$ & & & & 1.254 & $1.065-1.477$ & $0.007 *$ \\
\hline$\geq 20$ years (Non-teen) & - & - & - & 1.000 & (Reference) & - \\
\hline Antenatal attendance & - & - & $<0.001 *$ & - & - & $<0.001^{*}$ \\
\hline No antenatal attendance & 9.049 & $7.293-11.228$ & $<0.001 *$ & 10.028 & $6.892-14.591$ & $<0.001 *$ \\
\hline 1-3 attendance & 1.754 & $1.462-2.103$ & $<0.001 *$ & 2.164 & $1.751-2.675$ & $<0.001 *$ \\
\hline$\geq 4$ attendance & 1.000 & (Reference) & - & 1.000 & (Reference) & - \\
\hline Wealth index & - & - & $<0.001 *$ & - & - & $<0.001 *$ \\
\hline Poor & 2.059 & $1.585-2.675$ & $<0.001 *$ & 3.038 & $2.049-4.505$ & $<0.001 *$ \\
\hline Middle & 1.422 & $1.151-1.756$ & $0.001 *$ & 1.904 & $1.464-2.476$ & $<0.001 *$ \\
\hline Rich & 1.000 & (Reference) & - & 1.000 & (Reference) & - \\
\hline Religion & - & - & $0.020^{*}$ & - & - & $<0.001 *$ \\
\hline Traditionalist/other & 0.875 & $0.438-1.748$ & 0.706 & 3.028 & $1.191-7.695$ & $0.020 *$ \\
\hline Islam & 1.562 & $1.105-2.207$ & $0.012^{*}$ & 1.785 & $1.360-2.343$ & $<0.001 *$ \\
\hline Christianity & 1.000 & (Reference) & - & 1.000 & (Reference) & - \\
\hline Region of residence & - & - & $<0.001 *$ & - & - & $<0.001^{*}$ \\
\hline North-Central & 2.272 & $1.427-3.616$ & $0.001 *$ & 1.104 & $0.671-1.817$ & 0.696 \\
\hline North-East & 4.546 & $2.684-7.700$ & $<0.001 *$ & 2.500 & $1.440-4.340$ & $0.001^{*}$ \\
\hline North-West & 6.448 & $3.535-11.764$ & $<0.001 *$ & 4.187 & $2.654-6.605$ & $<0.001 *$ \\
\hline South-West & 1.238 & $0.764-2.005$ & 0.385 & 1.415 & $0.922-2.173$ & 0.112 \\
\hline South-South & 4.504 & $3.029-6.697$ & $<0.001 *$ & 2.756 & $1.710-4.441$ & $<0.001 *$ \\
\hline South-East & 1.000 & (Reference) & - & 1.000 & (Reference) & - \\
\hline
\end{tabular}

*Statistically significant at 5\% significance level. AOR: Adjusted Odds Ratio. CI: Confidence interval. 